\title{
Smart energy systems in China and Denmark
}

\author{
Jin Tan,' Qiuwei Wu!' Jacob Østergaard' and Yibo Wang² \\ 'Center for Electric Power and Energy, Department of Electrical Engineering, Technical University of Denmark; \\ Institute of Electrical Engineering, Chinese Academy of Sciences
}

\section{Introduction}

Energy plays an important role in the development of society. Before the industrial revolution, biomass (i.e., wood) was the world's main primary energy source. Since 1900, most primary energy came from wood and coal (Smil 2010), but with the advent of the automobile and airplanes in the early twentieth century, oil became the dominant fuel. In 2018, most of the world's energy was generated from fossil fuels (81\%). The rest came from bioenergy, including traditional solid biomass (9.4\%), nuclear (5\%), hydro (2.5\%) and other renewables, such as wind, solar, and geothermal (2.1\%) (World Energy Outlook 2019). In recent years, with growing environmental concerns, especially over global climate change and local pollution, attention in international agreements to reducing greenhouse gas (GHG) emissions and cleaning air, with a consequential increase of renewable energy technologies, has increased. Therefore, many countries are making serious efforts to shift from fossil fuels such as oil and coal to renewable energy sources (RES). China as well as Denmark are interesting countries in this respect. Denmark has been a pioneer in implementing renewable energy, and the Danish energy system has undergone a transformational change, while China ranked first in the world in terms of cumulative and new installations of onshore wind power by 2018 (He et al. 2020).

Since major renewable sources like wind and solar can easily be turned into electricity, and electric power can easily be transmitted, transformed, and used, it is expected to become the dominant energy carrier in the future. In recent years, wind power and photovoltaic (PV) power have been growing rapidly in many counties. Fig. 1 shows China's cumulative installed wind-power capacity from 2004 to 2019, which reached about $236 \mathrm{GW}$ in the latter year, accounting for almost $36 \%$ of total installed wind capacity worldwide (Global Wind Report 2019). It is estimated that over 25\% of new offshore wind-power capacity will be added in China by 2030 (REVE 2020). In Denmark, cumulative wind power capacity was $6.13 \mathrm{GW}$ in 2019, with onshore and offshore wind-turbine capacities reaching 4.43 GW and $1.70 \mathrm{GW}$ respectively (Wind Europe 2019). In addition, wind-power production accounted for $47.2 \%$ of Denmark's domestic electricity supply. Fig. 2 shows the proportion of onshore and offshore wind power, as well as the total wind-power share of electricity supply in Denmark between 2011 and 2019.
It should be noted that the power output of renewable technologies like wind and solar PV fluctuates due to rapidly changing meteorological conditions. Because they have a zero marginal cost, renewable power from wind and $P V$ is replacing conventional thermal power plants, which conventionally have been responsible for providing many electrical power system services, such as reserves, voltage control, frequency control, stability services, and black start restoration (Hansen and Søndergaard 2015). The increasing penetration of these renewable power sources is therefore posing substantial challenges to the planning, secure and reliable operation, and control of power systems (Tang et al. 2017, Zhang et al. 2014). Hence, the requirements for the flexibility to accommodate large amounts of naturally fluctuating renewable energy (often referred to as VRE) are increasing.l

In several countries and regions, parts of the gas, heating, cooling and transportation systems have responded to these flexibility requirements by means of a deep coupling of multiple energy sectors. Indeed, due to the intrinsic storage capabilities of, for example, the thermal inertia of district heating pipes and buildings (Liu et al. 2019), the storage of electric vehicle batteries (Mathiesen et al. 2008) and various energy-conversion techniques (e.g., power to heat, power to gas, CHP units), the heating and gas sectors can provide extra flexibility to the electric power system (EPS). Different energy sectors are coupled at the production or demand side.

The integration of different energy sectors can solve some challenges to the stable and reliable operation of electric power systems with high penetrations of renewable energy (Pinson et al. 2017). This will not only facilitate the integration of renewable energy, it can also improve the cost efficiency of the whole energy system if done properly. In Denmark, Energinet is the transmission system operator (TSO) of the country's electricity and gas transmission grids (Hansen and Søndergaard 2015), which, by controlling both wholesale grid systems, basically demonstrates the integration of two different energy systems. In addition,

\footnotetext{
1 It is customary to refer to 'naturally fluctuating renewable energy sources' as VRE, or 'variable renewable energy'. However, when doing so, it should be clear that the VRE is not only (deterministically) variable, but that the variation is mostly stochastic and only partially predictable.
} 


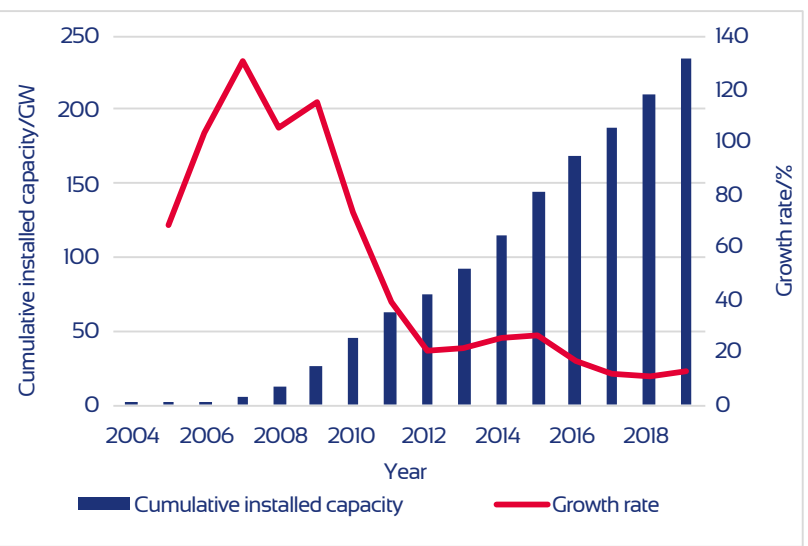

Figure 1 Cumulative installed wind power capacity in China (Source: He et al. 202O)

the Danish Partnership Smart Energy Networks was established in 2014 to bring together Danish energy companies, industry and knowledge institutions within electricity, heating, cooling and gas. This promises to be an effective approach for achieving the ambitious Danish climate and energy goal of a fully $100 \%$ renewable-based energy system by 2050 (Partnership Smart Energy Networks 2015).

In addition to the integration of infrastructural technology, coordinated operation and control of an integrated energy system are necessary (Li et al. 2015, He et al. 2015). At present, in most countries, the regulation and management of different energy sectors are still separate both for historical reasons and due to the different sets of rules based on diverse principles. This lack of uniform standardization impedes the development of efficient integration and optimal solutions for the whole system. Well-functioning and efficient smart energy systems should be based on an integrated energy-system approach that incorporates novel digital solutions, including sensors and actuators embedded in the system, various internet technologies, platforms with service-based designs, and novel business models (Lund et al. 2017), but this can only work effectively if the cross-sector regulations are compatible.

During the last few decades, the concept of the Smart Grid has emerged. It involves new concepts and technologies in the EPS. The European Union Commission Task Force for Smart Grids (2010) defines the smart grid as 'an electricity network that can cost-efficiently integrate the behavior and actions of all users connected to it - generators, consumers and those that do both - in order to ensure an economically efficient, sustainable power system with low losses and high levels of quality and security of supply and safety'. The idea of the smart grid can be extended to smart energy, whereby information and communication technology also play an important role in enhancing the performance of the coordinated operation and control of all the coupled energy sectors (Yu et al. 2016).

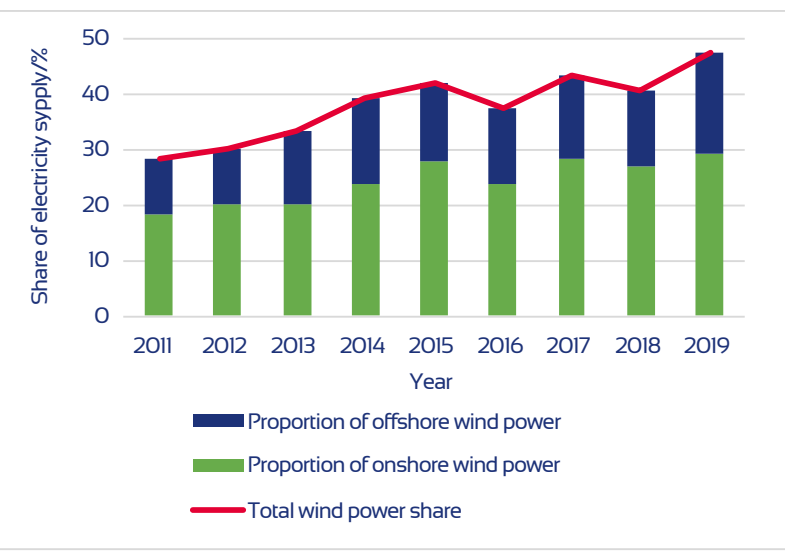

Figure 2 Proportion of onshore and offshore wind power and the total wind-power share of electricity supply in Denmark (Source: Energy Watch 2019)

\section{Smart energy system}

A 'smart energy system' is defined as a cost-effective, sustainable and secure energy system in which renewable energy production, infrastructure and consumption are integrated and coordinated through energy services, active users and enabling technologies (Partnership Smart Energy Networks 2015). Fig. 3 gives an overview of a Danish smart energy system providing flexibility for the cost-effective integration of renewable energies (DTU Sector Development Report 2020). The different characteristics of the coupled electricity, heating, and gas energy sectors in smart energy systems are listed in Table 1. An introductory semi-detailed introduction is provided below.

\section{Electricity sector}

There will be more naturally fluctuating power generation in the EPS, which can flow bi-directionally, from large-scale generators via the grid to the consumer, and be reinjected by prosumers into the grid. In addition, over time, small-scale distributed generation and fluctuating renewable generation will gradually replace the conventional central power plants. Since the traditional (largescale) synchronous electricity generation units that provide inertia response are being replaced by non-synchronous renewable-energy technologies (effectively via power-electronics inverters), the total inertia in the system is being reduced, leading in turn to adverse impacts on the frequency security of the EPS (Teng et al. 2015). This considerably increases the requirement for flexibility, especially frequency control reserves (FCR), to maintain the system frequency security. To obtain additional flexibility to support the operation and control of the EPS, new energy-conversion techniques, demand response, and new power-generation scheduling strategies are being introduced into the electricity sector. The conversion techniques include the still conventional gasfired electric power plants (gas-to-power) and cogeneration plants (gas-to-heat and electrical power), as well as heat pumps (electric power-to-heat) and future technologies that convert electrical energy into molecules such as hydrogen and methane (power-to-gas) (Guelpa et al. 2019). By promoting appropriate interaction between 
electric power generation and active consumers (including commercial, industry and residential), demand response can offer great benefits to operation of the system (Siano 2014). The electrical loads are controlled by intelligent management systems participating in the electricity markets. As an example, in the EU-supported project EcoGrid EU, flexibility on the consumer side is supposed to originate mainly from local heating systems in buildings (Zhang et al. 2019).

\section{Heating and cooling sector}

With the further development of low-energy buildings, residential and office energy consumption, including heating and cooling demand, will fall correspondingly. By developing more district heating and cooling systems where appropriate and justified, it is possible to move towards a more sustainable energy system based on renewable energy (Zong et al. 2019). In this regard, the concept of a 4th Generation District Heating System (4GDH) was proposed in Denmark (Lund et al. 2014), while the 5th Generation District Heating System (5CDH) was developed further, also known as Cold District Heating Networks (Wirtz et al. 2019). These systems are based on the idea of low-temperature and ultra-low-temperature district heating systems (DHS) respectively, which can reuse the waste heat from industry and buildings, as well as reduce heat loss. The heating networks in $4 \mathrm{GDH}$ are characterized by normal distribution temperatures of $50^{\circ} \mathrm{C}$ (supply pipe) and $20^{\circ} \mathrm{C}$ (return pipe) as annual averages, while the temperatures in pipes with $5 \mathrm{CDH}$ are around $5-30^{\circ} \mathrm{C}$, which keeps heat loss to a minimum and reduces the need for extensive insulation. In 5CDH, electrical heat-boosters are usually installed at the building side for heating hot tap-water. In addition, heat storage is playing an increasingly important role in the heating sector, which can enhance the flexibility of CHP units and integrate fluctuating wind power better through the conversion of electrical energy into heat.

\section{Natural gas sector}

Due to the low cost of the energy carrier, low environmental emissions, and high efficiency of natural gas-based technologies, natural gas has become the second largest source of the world energy consumption (He et al. 2018). On the one hand, gas can easily be converted into electricity and heat by gasfired power generation, such as combined cycle gas turbines (CCGTs), high-efficiency condensing boilers, and combined heat and power (CHP). CHP (or co-generation) intensifies the coupling between the natural gas and electricity power systems. On the other hand, with the hopefully successful future development of power to gas (P2G) technology, electric power can also be converted into gas (hydrogen and methane), and then the converted gas can be injected into the natural gas system together with biogas (Zeng et al. 2017). It should be noted, however, that although the overall efficiency of this process is quite low, it may nevertheless be a necessary building block in achieving the required system integration between sectors to ensure long-term storage. The P2G route can help decrease the curtailing of renewable energies and provide more flexibility for the EPS. Furthermore, the natural-gas system has large-scale storage capabilities due to the pressure flexibility and the large volumes in pipelines and caverns (Hansen and Søndergaard 2015).

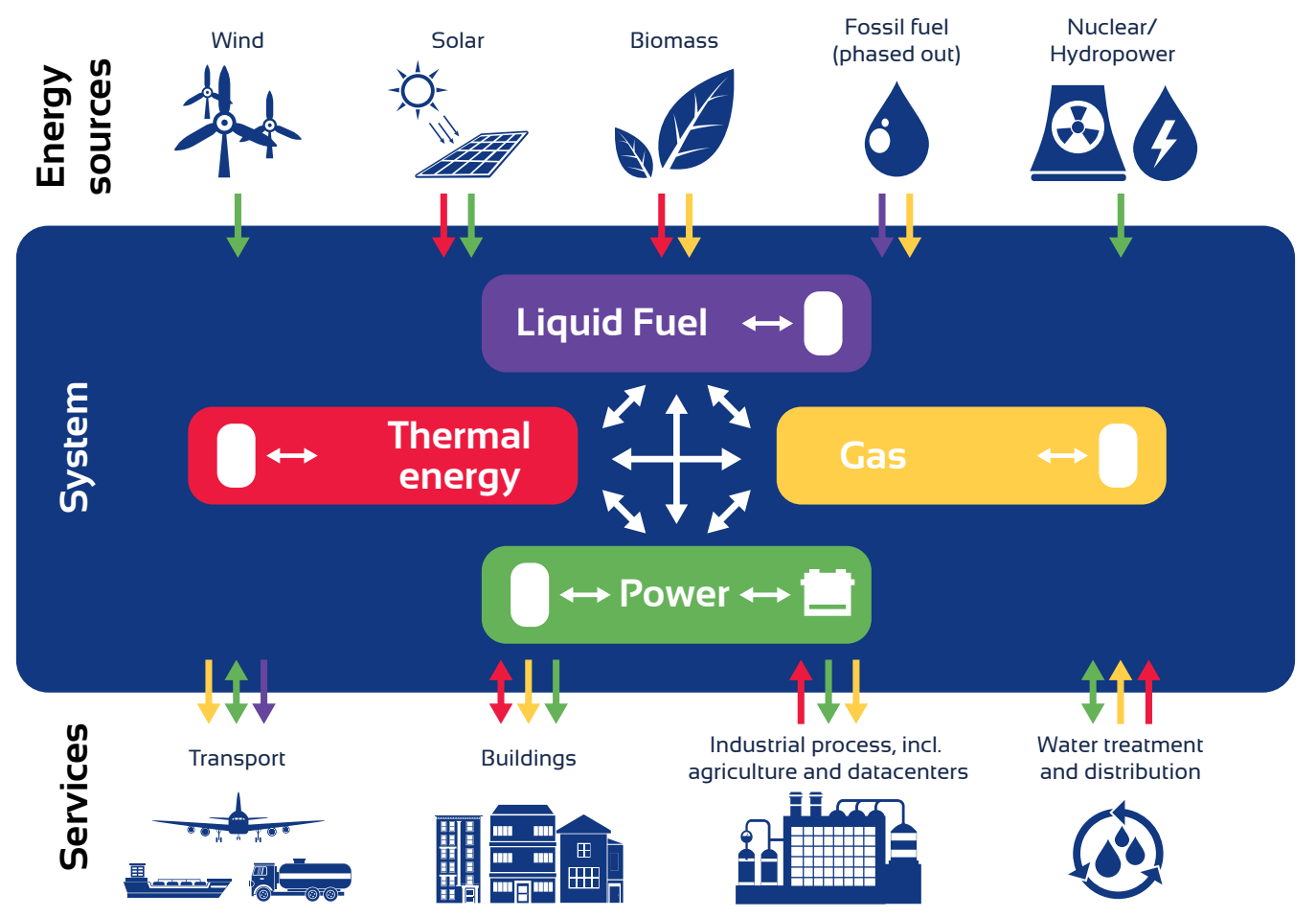

Figure 3 Overview of integrated energy system (Source: DTU Sector Development Report) 


\section{Transportation sector}

The European Environmental Agency (EEA), which keeps track of worldwide final energy consumption, has found that the transport sector is responsible for about a third of overall final energy consumption (Shell International BV 2017). Thus, because of the accompanying CO2 emissions and local pollution, it is crucial that the transportation sector replaces fossil fuels with renewable-based energy carriers (Qian et al. 2020). The electrification of transportation through battery electric vehicles (BEVs) or fuel-cell hybrid electric vehicles $(\mathrm{HEV})$ are promising technologies, since they can reduce fossil-fuel consumption, as well as enhancing the integration of naturally fluctuating renewable energies. For instance, BEVs can be charged and discharged at different times and locations. Thus, it is treated as a flexible load (G2V) and storage in the power system, which can change the load both in time and space (Knezović et al. 2017). Meanwhile, BEVs can discharge electric power to the power system like generation units through vehicle to grid (V2G) technology. With the proper design and control strategies, BEVs can provide multiple ancillary services to the power system, such as frequency response (Askjar et al. 2020).

\section{Operation of smart energy systems}

The optimal operation and smart control of smart energy systems can improve the sustainability, reliability, and cost efficiency of the whole system. Taking into account diverse energy-conversion technologies and the coordination of different energy sectors, the energy services required by customers or system operators can be provided in many different ways. With centralized control, the entire smart energy system is generally managed by a single operator, and overall the appropriate operation constitutes a large-scale centralized problem, which is more complicated than with an individual system. To improve computation efficiency and protect information privacy, distributed or decentralized solutions are desired to achieve independent yet coordinated operation (Tan et al. 2020). In addition, there will be quite a lot of local control via integra- tors and aggregators, which also requires distributed operation and control. Apart from the aforementioned technical aspects, a proper market design with the right incentives and clear (i.e. stimulating and no -mutually opposing) regulations will be required to ensure the effective operation of smart energy systems as well.

\section{Current status of smart energy systems in China and Denmark}

\section{Current status of smart energy systems in China}

During the period of the 12th Five-Year Plan (2011-2015), coal consumption in China fell by $5.2 \%$ and the consumption of non-fossil fuels increased by $2.6 \%$ (The development of energy in China 2018). Before 2006, electricity generation came mainly from conventional thermal power units and hydropower units. In order to reduce $\mathrm{CO} 2$ emissions, power generation from renewable sources of energy such as wind, solar and hydro has developed rapidly in China during the last decade. It is expected that carbon dioxide (CO2) emissions will peak at around 2030 and that the non-fossil-fuel share of primary energy will increase to $20 \%$ by the same year (International Energy Agency 2017). Moreover, the Chinese government has recently announced a target of achieving carbon neutrality by 2060. In addition, due to its higher conversion efficiency and lower environmental emissions, natural gas has attracted increasing attention, expecting to reach $15 \%$ of total fuel consumption in the whole energy sector by 2030. In northern China, the $\mathrm{DHS}$ is being adopted to supply heat to consumers. The combined heat and power (CHP) units and heat boilers cover $62.9 \%$ and $35.7 \%$ of heating production respectiveIy, the rest mainly being supplied by industry waste heat and geothermal. However, the electric power and heat generation of CHP units depends on heat loads, which limits the operational region of the CHP units. CHP units must run when the heat is needed, leading to a high curtailment of wind power in the winter.

Since 2015, the National Energy Administration of China has issued several policies to support the de-

Table 1 Different characteristics of various energy sectors. Source: Hvidtfeldt et al. 2015

\section{Energy sectors}

\begin{tabular}{|c|c|c|c|}
\hline entergy sectors & & & \\
\hline Electricity & $\begin{array}{l}\text { Long-distance transport } \\
\text { Low losses } \\
\text { Easy to generate from renewable energy sources } \\
\text { Easy conversion to other energy carriers }\end{array}$ & Very low (seconds) & High \\
\hline Heating & $\begin{array}{c}\text { Local/district } \\
\text { Medium losses } \\
\text { Difficult to convert to other energy carriers } \\
\text { (if low temperature) }\end{array}$ & Medium (days) & Medium \\
\hline Gas & $\begin{array}{l}\text { Long-distance transport } \\
\text { Low transmission losses } \\
\text { Intrinsic losses during conversion at the point of use } \\
\text { Easy to convert to heat and electricity }\end{array}$ & High (months) & Low \\
\hline
\end{tabular}


velopment of smart energy systems, including microgrids with high renewable penetration and an overall integrated energy system, referred to as the Energy Internet. The State Grid Tianjin Electricity Power Company is the first company to conduct demonstration projects of integrated energy systems, which would achieve coordinated management and control of the electricity, heating and cooling fluxes and flows. The integrated energy system, if done properly, improves the cost efficiency of the whole system and reduces CO2 emissions. The State Grid Jiangsu Electricity Power Company has completed a demonstration project of a district smart energy system with 70\% penetration of renewables, which incorporates the electricity, heating, cooling, and transportation energy sectors. In addition, the China Southern Power Grid has investigated how to design and operate a smart energy system that includes the electricity, heating, gas, and transportation energy sectors. However, at present the EPS, DHS and gas systems are operated by different entities in China and are thus planned individually.

\section{Current status of smart energy systems in Denmark}

In 2018, electricity from renewables accounted for $60 \%$ of Denmark's domestic electricity supply, and wind power accounted for 40\% (Danish Energy Agency 2018). In particular, the transition from fossil fuels to renewable energy for district heating is significant in Denmark. The percentage of renewables covered 60\% of district heating production in 2018 (Danish Energy Agency 2018). Apart from securing adequate capacity through the connection with neighboring countries, the heating sector in Denmark plays a major role to provide flexibility for the EPS in integrating fluctuating wind power. The heating and electricity sectors are coupled through CHP plants, which generate around $70 \%$ of thermal energy in the Danish DHS. Since the electricity tax is being reduced gradually over time, electric boilers and heat pumps have attracted increasing attention. Combined with the electric boilers, heat pumps, and heat storage, CHP units can provide more flexibility to the EPS.

In order to facilitate the integration of wind power, Denmark has conducted quite a number of research projects on future smart energy systems. For example, the EnergyLab Nordhavn project is a demonstration project for a dense and integrated future energy system. It demonstrates how electricity and heating, energy-efficient buildings and electric transportation with the innovative use of data and analytics can be integrated into an intelligent, flexible and optimized energy system (A Smart City Energy Lab 2019). A low-temperature district-heating (LTDH) system incorporating smart energy network technologies, heat storage, energy-flexible buildings, decentralized supply options and fuel-shift solutions, has been developed. In the Copenhagen Nordhavn area, active participation by the occupants of the low-energy buildings acting as agile consumers and users, and therefore becoming active energy-flexible elements, has been investigated. Another project, 'Centre for IT-Intelligent Energy Systems (CITIES)', has developed methodologies and digital solutions for the analysis, operation and development of integrated urban energy systems, with the ultimately aim of achieving independence from fossil fuels by utilizing the flexibility of the energy system through intelligence, integration, and planning (Centre for IT-Intelligent Energy Systems in cities). The EnergyPlan tool has been developed by Aalborg University to design a $100 \%$ renewable-energy system that includes the electricity, heating, cooling, transportation and industrial sectors. It is investigating the modelling of all relevant energy-generation units, energy storage, and energy-conversion technologies (Lund 2010).

\section{Recommendations for the further development of smart energy systems in China and Denmark}

An efficient transition to a smart energy system requires intensive research and development efforts regarding the integration of various energy-conversion techniques, system operation frameworks, digitalization and communication systems etc. The following suggestions for further research into and development of smart energy systems are recommended for both China and Denmark:

1. Investigate new optimal operation frameworks and control strategies for multiple energy systems. Given the fact that various energy sectors are managed by different entities and that the coordination of different energy sectors is insufficient at present, research should be conducted to coordinate various energy sectors with different operational time scales and characteristics, while respecting the privacy of different entities. The development of smart energy systems should focus on providing secure and reliable energy services to end-users.

2. Design multi-energy carrier markets and develop new business model frameworks. In order to distribute smart energy system costs and benefits across energy sectors and services efficiently, new regulations and business models should be developed. A corresponding demonstration acting as operational platforms for new business models is needed. In addition, the incentives needed for energy consumers and building management to adopt flexible consumption should be explored.

3. Develop solutions for the more efficient integration of energy storage and advanced energy-conversion technologies to accommodate the growth in fluctuating renewable energy. The optimal operation and smart control of the various energy infrastructures should be investigated in depth, enabling additional flexibility across these infrastructures to efficiently balance and utilize renewable energy, mainly integrated into the power system. 
4. Design and develop low-energy buildings for a green transition. Buildings play an important role as the main consumers in cities. Together with indoor climates and thermal inertia, the potential flexibility of buildings can be utilized. Advanced building energy management and control systems should be developed to interact with the (external) smart energy system and increase energy flexibility.

5. Develop integrated design and planning methods across energy sectors for smart energy systems. At present, there are no national policies and regulations regarding smart energy systems in either China or Denmark. The coordinated design and planning should evolve to remove the barriers between the different energy sectors and facilitate the deployment of smart energy solutions.

However, since China's current multi-energy system is not as developed as that in Denmark, there are additional challenges in China in developing smart energy systems:

1. The electric power system in China is undergoing market reform, and the regulations corresponding to the demand side have not yet been enforced. It is currently unclear how smart energy systems can participate in the market and make a profit by providing energy services.

2. For the time being, the 2 nd generation of DHS supplies heating to consumers in China. These thermal network systems need to be upgraded to 4th- and 5th-generation DHS to improve energy efficiency and reduce environmental emissions, whereby the supply and return temperatures are reduced and more heat storage is included. Moreover, heating production should be generated increasingly from renewable and clean energies such as biomass.

\section{Conclusion}

Cross-sector smart energy systems will be developed in Denmark, China and the rest of the world. The integrated energy system will be the most efficient solution to the problem of increasing the energy efficiency of systems and reducing environmental emissions. This chapter has described the concept of the smart energy system, integrating the electricity, heating, cooling, gas, and transportation sectors with high renewable-energy penetration. The different timescales and characteristics of the different energy sectors create challenges for the coordinated operation of the different energy sectors.

Denmark and China are both dedicated to the development of smart energy systems in order to realize their commitment to mitigating climate change. Many projects have been conducted to demonstrate the economic and environmental benefits of smart energy systems. Compared to the extensive investigation of integrated energy systems and well-developed district-heating supply in Denmark, the development of smart energy systems in China is still at the beginning stage. Further research and development are required in both Denmark and China to deal with the challenges to the green transition towards a smart energy system, including advanced technologies, novel market designs and business models, as well as consistent national regulations to remove the barriers between the different energy sectors

\section{References}

A Smart City Energy Lab. 2019. Available at: http://www. energylabnordhavn.com/

Askjar, R. J. et al. 2020. 'Demonstration of a Technology Neutral Control Architecture for Providing Frequency Control Using Unidirectional Charging of Electric Vehicles', 2020 55th International Universities Power Engineering Conference (UPEC): pp. 1-6.

Centre for IT-Intelligent Energy Systems in cities. n.d. Available at: https://smart-cities-centre.org/
Chen, X., McElroy, M. B. and Kang, C. 2018. 'Integrated Energy Systems for Higher Wind Penetration in China: Formulation, Implementation, and Impacts', IEEE Transactions on Power Systems, 33(2): pp. 1309-1319.

Danish Energy Agency. 2018. 'Energy Statistics 2018'. Available at: https://ens.dk/sites/ens.dk/files/Statistik/ energy_statistics_2018.pdf

DTU Sector Development Report. Smart Energy Systems are the way forward. Available at: https:// www.dtu.dk/samarbejde/ais-artikler/2018/11/sektorudviklingsprojekt-om-smarte-energisystemer?id=66478bla-baea-4db3-8c17-ded6lecd8b91 
Energy watch. 2019. 'Danish wind broke record in 2019' Available at: https://energywatch.eu/EnergyNews/Renewables/articlell852556.ece

EU Commission Task Force for Smart Grids. 2010. Available at: http://www.ieadsm.org/wp/files/Tasks/Task\%20 17\%20-\%2OIntegration\%20of\%2ODemand\%20Side\%20 Management,\%2OEnergy\%2OEfficiency,\%2ODistributed\%20Generation\%20and\%2ORenewable\%20Energy\%20 Sources/Background\%2Omaterial/Egl\%2Odocument\%20 v_24sep2010\%20conf.pdf

Global Wind Report. 2019. Available at: https://gwec.net/

Guelpa, E., Bischi, A., Verda, V., Chertkov, M. and Lund, H. 2019. 'Towards future infrastructures for sustainable multi-energy systems: A review', Energy. 184: pp. 2-21.

He, C., Wu, L., Liu, T., Wei, W. and Wang, C. 2015. 'Transmission-Constrained Unit Commitment Considering Combined Electricity and District Heating Networks', IEEE Transactions on Sustainable Energy. IEEE, 7(2): pP. 480-492.

He, Y., Yan, M., Shahidehpour, M., Li, Z., Guo, C., Wu, L. and Ding, Y. 2018. 'Decentralized Optimization of Multi-Area Electricity-Natural Gas Flows Based on Cone Reformulation', IEEE Transactions on Power Systems. IEEE, 33(4): pp. 4531-4542.

He, Z., Drozdov, D., Wang, J., Shen, W., Li, C. and Li, W. 2020 'Competitiveness of the wind power industry in China: An analysis based on the extended Diamond Model', J. Renewable Sustainable Energy.

Hvidtfeldt, L. H., Leif, S. P. 2015. 'DTU International Energy Report 2015 : Energy systems integration for the transition to non-fossil energy systems' [online]. Available at: https://backend.orbit.dtu.dk/ws/portalfiles/portal/119583507/DTU_International_Energy_Report_2015_ rev.pdf.

International Energy Agency. 2017. World Energy Outlook 2017. Available at: https://webstore.iea.org/download/direct/1055?fileName=World_Energy_Outlook_2017.pdf

International Energy Agency. 2019. World Energy Outlook 2019. Available at: https://www.iea.org/reports/world-energy-outlook-2019

Knezović, K. et al. 2017. 'Supporting involvement of electric vehicles in distribution grids: Lowering the barriers for a proactive integration', Energy, 134: pp. 458-468.

Li, Z., Wu, W., Wang, J., Zhang, B. and Zheng, T. 2015. Transmission-Constrained Unit Commitment Considering Combined Electricity and District Heating Networks', IEEE Transactions on Sustainable Energy. IEEE, 7(2): pp. 480-492.
Liu, G., Jiang, T., Ollis, T. B., Zhang, X. and Tomsovic, K. 2019. 'Distributed energy management for community microgrids considering network operational constraints and building thermal dynamics', Applied Energy. 239: pp. 83-95.

Lund H. 2010. 'EnergyPLAN: advanced energy systems analysis computer model'. Retrieved from http://energy. plan.aau.dk/EnergyPLAN-Version8-February2010.pdf

Lund, H., Østergaard, P. A., Connolly, D. and Mathiesen, B. $\checkmark$. 2017. 'Smart energy and smart energy systems', Energy 137: pp. 556-565.

Lund, H., Werner, S., Wiltshire, R., Svendsen, S., Eric, J., Hvelplund, F. and Vad, B. 2014. '4th Generation District Heating (4GDH) Integrating smart thermal grids into future sustainable energy systems', Energy. 68: pp. 1-11.

Mathiesen, B. V., Lund, H. and Nørgaard, P. 2008. 'Integrated transport and renewable energy systems', Utilities Policy, 16(2): pp. 107-116.

Pinson, P., Mitridati, L., Ordoudis, C. and Ostergaard, J. 2017. 'Towards fully renewable energy systems: Experience and trends in Denmark', CSEE Journal of Power and Energy Systems, 3(1): pp. 26-35.

Qian, T. et al. 2020. 'Enhanced Coordinated Operations of Electric Power and Transportation Networks via EV Charging Services', IEEE Transactions on Smart Grid. 11(4): pp. 3019-3030

REVE. 2020. 'China to account for over 25\% global offshore wind power capacity by 2030'. Available at: https:// www.evwind.es/2020/08/25/china-to-account-for-over25-global-offshore-wind-power-capacity-by-2030/76767

Shell International BV. 2017 'Shell - World Energy Model - A View To 2100'. Available at: https://www.shell.com/ energy-and-innovation/the-energy-future/scenarios/ shell-scenarios-energy-models/world-energy-model/_ jcr_content/par/textimage.stream/1510344160326/2ee82a9c68cd84e572c9db09cc43d7ec3e3fafe7/ shell-world-energy-model.pdf

Siano, P. 2014. 'Demand response and smart grids: A survey', Renewable and Sustainable Energy Reviews. 30: pp. 461-478

Smil, V. 2010. Energy transitions: history, requirements, prospects. Praeger Publishers.

Tan, J., Wu, Q., Wei, W., Liu, F., Li, C. and Zhou, B. 2020 'Decentralized robust energy and reserve Co-optimization for multiple integrated electricity and heating systems', Energy. 205: p. 118040

Tang, C., Xu, J., Sun, Y., Liu, J., Li, X., Ke, D., Yang, J. and Peng, X. 2017. 'A Versatile Mixture Distribution and Its Application in Economic Dispatch with Multiple Wind Farms', IEEE Transactions on Sustainable Energy, 8(4): pp. 1747-1762. 
Teng, F., Trovato, V. and Strbac, G. 2015. 'Stochastic Scheduling with Inertia-dependent Frequency Regulation', IEEE Transactions on Power System, pp. 1-10.

The development of energy in China. 2018. (in Chinese) Available at: http://www.chyxx.com/industry/201802/611045.html

The Partnership Smart Energy Networks. 2015. 'Vision for Smart Energy in Denmark' [online]. Available at: https:// ens.dk/sites/ens.dk/files/Forskning_og_udvikling/vision_for_smart_energy_in_denmark_2015.pdf

Wang, J., Zong, Y., You, S. and Træholt, C. 2017. 'A review of Danish integrated multi-energy system flexibility options for high wind power penetration', Clean Energy, 1(1): pp. 23-35.

Wind Europe. 2019. 'Wind energy in Europe in 2019'. Available at: https://windeurope.org/wp-content/uploads/ files/about-wind/statistics/WindEurope-Annual-Statistics-2019.pdf

Wirtz, M. et al. 2020. '5th Generation District Heating: A novel design approach based on mathematical optimization', Applied Energy. 260: pp. 114158.
Yu, X., Xu, X., Chen, S., Wu, J. and Jia, H. 2016. 'A brief review to integrated energy system and energy internet', Diangong Jishu Xuebao/Transactions of China Electrotechnical Society, pp. 1-13.

Zeng, Q., Zhang, B., Fang, J. and Chen, Z. 2017. 'A bi-level programming for multistage co-expansion planning of the integrated gas and electricity system', Applied Energy. 200: pp. 192-203.

Zhang, L., Good, N. and Mancarella, P. 2019. 'Building-togrid flexibility: Modelling and assessment metrics for residential demand response from heat pump aggregations', Applied Energy. 233-234: pp. 709-723.

Zhang, N., Kang, C., Xia, Q. and Liang, J. 2014. 'Modeling conditional forecast error for wind power in generation scheduling', IEEE Transactions on Power Systems. 29(3): pp. 1316-1324.

Zong, Y., You, S., Wang, J., Dong, Z. Y., Cai, H. and Træholt, C. 2019. 'Investigation of real-time flexibility of combined heat and power plants in district heating applications', Applied Energy. 237: pp. 196-209.

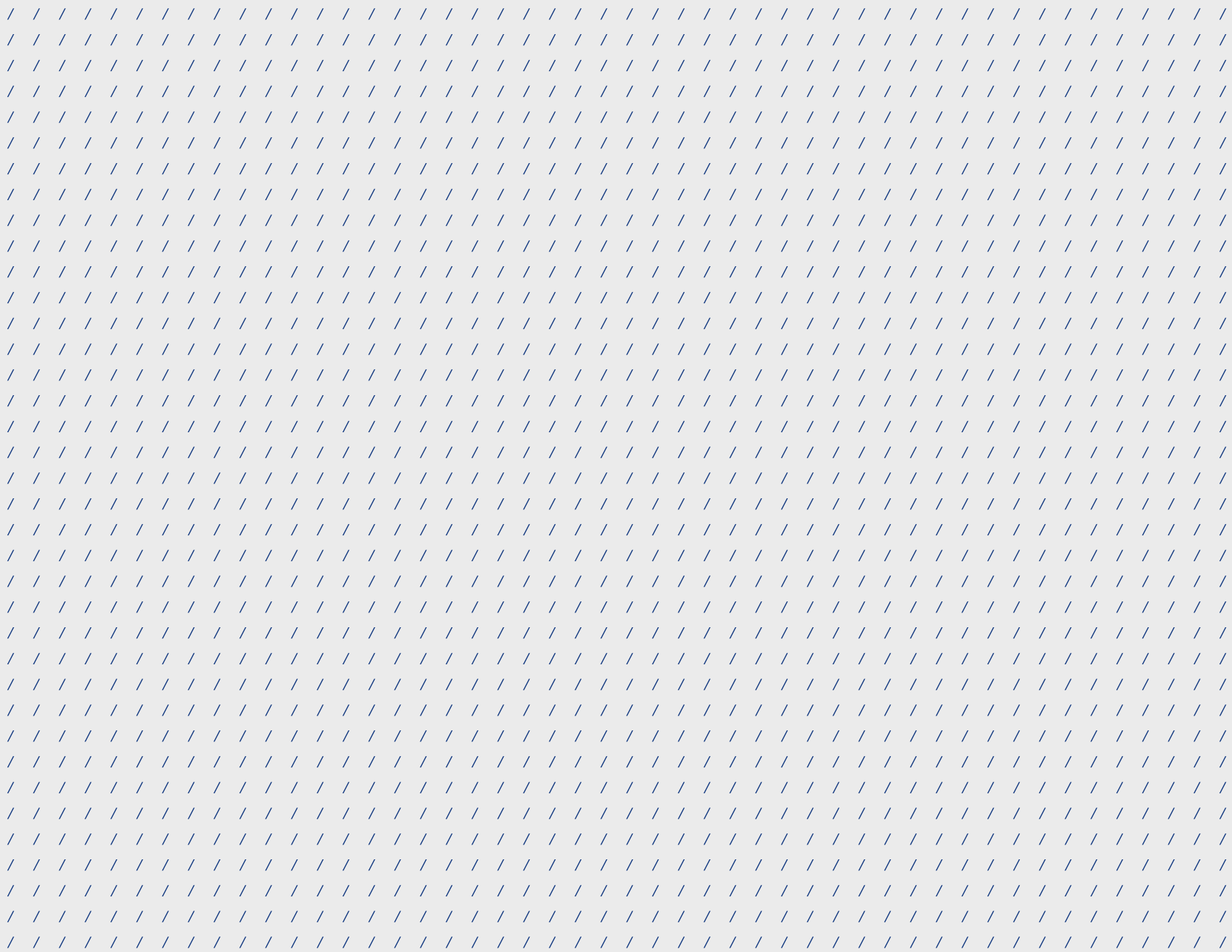

